JURNAL TEEKROSAINS

VOLUME 3

No. 1, 22 Desember 2013

Halaman 1-80

\title{
PENGARUH KHLORHEKSIDIN DIGLUKONAT 2\% DAN GLISERIN SEBAGAI BAHAN PENCAMPUR KALSIUM HIDROKSIDA TERHADAP SISA KALSIUM HIDROKSIDA PADA SEPERTIGA APIKAL DINDING SALURAN AKAR GIGI
}

\author{
Emmawati Prawitasari \\ Program Studi Ilmu Konservasi Gigi, Program Pendidikan Dokter Gigi Spesialis, Fakultas \\ Kedokteran Gigi Universitas Gadjah Mada Yogyakarta \\ Email: emma_ps83@yahoo.com. \\ Diatri Nari Ratih \\ Bagian Ilmu Konservasi Gigi, Fakultas Kedokteran Gigi \\ Universitas Gadjah Mada Yogyakarta \\ Widowati Siswomihardjo \\ Bagian Ilmu Biomaterial Kedokteran Gigi, Fakultas Kedokteran Gigi \\ Universitas Gadjah MadaYogyakarta
}

\begin{abstract}
The most widely used intracanal medicament is calcium hydroxide $\left(\mathrm{Ca}\left(\mathrm{OH}_{2}\right)\right.$. However, the residue of $\mathrm{Ca}(\mathrm{OH})_{2}$ in the root canal must be removed prior to obturation. The residue of $\mathrm{Ca}(\mathrm{OH})_{2}$ in the root canal walls would result in apical leakage. This is due to the unstable dimension of $\mathrm{Ca}(\mathrm{OH})_{2}$, reduced flow and working time of the sealers, and decreased adhesion of sealers and gutta percha to root canal walls. This study aimed to determine the effect of $\mathrm{Ca}(\mathrm{OH})_{2}$ vehicles and agitation irrigation techniques on the residue of $\mathrm{Ca}(\mathrm{OH})_{2}$ in the apical third of the root canal walls.

Twelve extracted mandibular first premolars were used in this study. The crowns of the teeth were removed at the apical part of cemento enamel junction with a length of $14 \mathrm{~mm}$ from the apical. The canals were prepared with a Step Back technique to obtain Master Apical File ( MAF ) \# 40. The specimens were randomly devided into groups $\mathrm{I}$, the pastes of $\mathrm{Ca}(\mathrm{OH})_{2}+$ chlorhexidine digluconate $2 \%$. In groups II, the pastes of $\mathrm{Ca}(\mathrm{OH})_{2}+$ glycerin were applied. Each specimen of the study was sectioned in the sagittal direction, then was photographed under a stereo microscope at $120 \mathrm{x}$ magnification. The percentages of $\mathrm{Ca}(\mathrm{OH})_{2}$ residue were calculated using UTHSCSA image tool 3 software. Data were analyzed using T-test at $95 \%$ level of significance.

The results revealed that the group of $\mathrm{Ca}(\mathrm{OH})_{2}+$ chlorhexidine digluconate $2 \%$ paste showed the lowest number of residual $\mathrm{Ca}(\mathrm{OH})_{2}$. The conclusion of this study was that the vehicles affected the total residue of $\mathrm{Ca}(\mathrm{OH})_{2}$.
\end{abstract}

Keywords: calcium hydroxide, chlorhexidine digluconate $2 \%$, glycerin, residual $\mathrm{Ca}(\mathrm{OH})_{2}$ 


\section{ABSTRAK}

Medikamen intrakanal yang paling banyak dipakai saat ini yaitu kalsium hidroksida $\left(\mathrm{Ca}(\mathrm{OH})_{2}\right)$, namun demikian sisa $\mathrm{Ca}(\mathrm{OH})_{2}$ dalam saluran akar gigi harus dihilangkan sebelum dilakukan obturasi. Sisa $\mathrm{Ca}(\mathrm{OH})_{2}$ pada dinding saluran akar gigi dapat menyebabkan kebocoran apikal. Hal ini disebabkan dimensi $\mathrm{Ca}(\mathrm{OH})_{2}$ yang tidak stabil, menurunkan daya alir dan working time siler, serta menurunkan pelekatan siler dan gutaperca terhadap dinding saluran akar gigi. Penelitian ini bertujuan untuk mengetahui pengaruh bahan pencampur $\mathrm{Ca}(\mathrm{OH})_{2}$ terhadap sisa $\mathrm{Ca}(\mathrm{OH})_{2}$ pada sepertiga apikal dinding saluran akar gigi.

Subjek penelitian menggunakan 12 gigi premolar pertama mandibula. Gigi dipotong di bawah cemento enamel junction dengan panjang $14 \mathrm{~mm}$ dari apikal. Seluruh gigi dilakukan preparasi saluran akar menggunakan teknik Step Back sampai didapatkan master apikal file (MAF) \#40. Subjek penelitian dikelompokkan menjadi kelompok I diaplikasikan pasta $\mathrm{Ca}(\mathrm{OH})_{2}{ }^{+}$ khlorheksidin diglukonat $2 \%$ dan kelompok II diaplikasikan pasta $\mathrm{Ca}(\mathrm{OH})_{2}+$ gliserin. Seluruh subjek penelitian dipotong dalam arah sagital, selanjutnya difoto di bawah mikroskop stereo dengan pembesaran 120x. Perhitungan luas sisa $\mathrm{Ca}(\mathrm{OH})_{2}$ menggunakan progran UTHSCSA versi 3. Data dianalisis menggunakan uji T-testdengan tingkat kemaknaan 95\%.

Hasil penelitian menunjukkan sisa $\mathrm{Ca}(\mathrm{OH})_{2}$ paling sedikit tampak pada kelompok aplikasi pasta $\mathrm{Ca}(\mathrm{OH})_{2}+\mathrm{khlorheksidin}$ diglukonat $2 \%$. Kesimpulan dari penelitian ini menunjukkan bahan pencampur berpengaruh terhadap sisa $\mathrm{Ca}(\mathrm{OH})_{2}$ pada dinding saluran akar gigi.

Kata kunci: kalsium hidroksida, khlorheksidin diglukonat 2\%, gliserin, sisa $\mathrm{Ca}(\mathrm{OH})_{2}$

\section{PENGANTAR}

Sebelum dilakukan obturasi, bahan medikamen intrakanal yaitu kalsium hidroksida $\left(\mathrm{Ca}(\mathrm{OH})_{2}\right)$ harus dihilangkan dari saluran akar gigi (Nandini dkk., 2006). Adanya sisa $\mathrm{Ca}(\mathrm{OH})_{2}$ dalam saluran akar gigi, dapat menyebabkan kebocoran apikal. Hal ini disebabkan karena dimensi $\mathrm{Ca}(\mathrm{OH})_{2}$ yang tidak stabil yaitu mudah larut dengan adanya cairan tubuli dentin dan jaringan periodontal (van der Sluis dkk., 2007). Kerugian lain dengan adanya sisa $\mathrm{Ca}(\mathrm{OH})_{2}$ akan mengurangi permeabilitas dentin sehinggamempengaruhi penetrasi siler ke dalam tubuli dentin (Rao dan Manasa, 2012). Penurunan permeabilitas dentin juga dapat mempengaruhi pelekatan siler dan bahan obturasi lain pada dinding saluran akar gigi (Hosoya dkk., 2004). Sisa $\mathrm{Ca}(\mathrm{OH})_{2}$ dapat menurunkan kekuatan dan kekerasan dentin (Kusuma dkk., 2013),serta dapat mengurangi daya alir dan working time siler (Hosoya dkk., 2004).

Pasta $\mathrm{Ca}(\mathrm{OH})_{2}$ bersifat thixotropic yaitu mampu mengalir dengan adanya getaran (agitasi) (Spangberg dan Haapasalo, 2002). Penggunaan teknik irigasi agitasi diharapkan lebih efektif dalam membersihkan $\mathrm{Ca}(\mathrm{OH})_{2}$ pada dinding saluran akar gigi. Teknik agitasi manual menggunakan jarum safe-ended dapat mengurangi angka kejadian ekstrusi bahan irigasi kejaringan periapikal. Jarum safe-ended juga meningkatkan kekuatan geser bahan irigasi terhadap dinding saluran akar gigi, sehingga dapat melepaskan debris dan smear layer yang menempel pada dinding saluran akar gigi. Teknik ini juga dapat menciptakan arus turbulen sehingga dapat meningkatkan kebersihan apikal (Boutsioukis dkk., 2010).

Bahan pencampur $\mathrm{Ca}(\mathrm{OH}){ }_{2}$ mempunyai peran dalam menentukan kecepatan disosiasi ion, kelarutan pada jaringan periapikal dan tubuli dentin saluran akar gigi. Berdasarkan viskositas, dikenal tiga jenis bahan pencampur yaitu encer, kental, dan berbahan dasar minyak. Khlorheksidin diglukonat merupakan salah satu bahan pencampur $\mathrm{Ca}(\mathrm{OH})_{2}$ dengan viskositas encer. Pada konsentrasi 2\%, khlorheksidin diglukonat bersifat bakterisid, yaitu efektif menghilangkan Enterococcus faecalis dan Candida albicans. Kombinasi $\mathrm{Ca}(\mathrm{OH})_{2}$ dengan pencampur khlorheksidin diglukonat akan meningkatkan sinergisme masing-masing sifat bahan. Hal ini disebabkan karena menghasilkan oksigen reaktif dan terjadinya deprotonasi. Bahan pencampur tipe encer akan menyebabkan ion $\mathrm{Ca}^{2+}$ dan $\mathrm{OH}^{-}$terurai 
dengan cepat serta menjadi lebih mudah larut saat berkontak dengan jaringan, namun dengan terjadinya deprotonasi khlorheksidin diglukonat maka akan meningkatkan viskositas pasta $\mathrm{Ca}(\mathrm{OH})_{2}$. Meningkatnya viskositas pasta $\mathrm{Ca}(\mathrm{OH})_{2}$ menyebabkan bahan ini berkontak lebih lama pada dinding saluran akar dibandingkan pencampuran dengan salin (Fava dan Saunder, 1999).

Gliserin dikelompokkan dalam bahan pencampur kental. Gliserin bersifat higroskopis, sehingga bahan ini mampu membawa $\mathrm{Ca}(\mathrm{OH})_{2}$ berpenetrasi ke dalam tubuli dentin (Khosy dkk., 2011). Serbuk $\mathrm{Ca}(\mathrm{OH})_{2}$ dicampur dengan gliserin mempunyai sifat kelarutan lebih rendah dibandingkan jika serbuk $\mathrm{Ca}(\mathrm{OH})_{2}$ dicampur dengan pelarut encer. Dengan sifat kelarutan yang rendah menyebabkan bahan ini tidak mudah keluar dari foramen apikal. Serbuk $\mathrm{Ca}(\mathrm{OH})_{2}$ jika dicampur dengan bahan yang lebih kental, maka dinding saluran akar akan lebih sulit dibersihkan dibanding dengan bahan pencampur encer karena sifatnya menjadi lebih lengket dan melekat erat dengan dinding saluran akar gigi (Nandini dkk., 2006; Hosoya dkk., 2004). Dari uraian di atas, masih terdapat kontroversi bahan pencampur $\mathrm{Ca}(\mathrm{OH})_{2}$ yang lebih mudah dihilangkan pada sepertiga apikal dinding saluran akar gigi.

Penelitian ini bertujuan untuk mengetahui pengaruh bahan pencampur kalsium hidroksida terhadap sisa kalsium hidroksida pada sepertiga apikal dinding saluran akar gigi. Hasil penelitian diharapkan dapat menjadi informasi di bidang kedokteran gigi dan sebagai pertimbangan operator dalam memilih bahan pencampur yang mampu membersihkan dinding saluran akar dengan optimal.

Sebanyak 12 gigi premolar satu mandibula dibersihkan dan disimpan dalam larutan salin sampai waktu dilakukan penelitian. Mahkota anatomis gigi dipotong dibawah cemento enamel junction dengan panjang $14 \mathrm{~mm}$ dari apikal menggunakan diskus intan. Saluran akar dilakukan preparasi teknik Step back menggunakan K-file sampai mendapatkan master apical file (MAF) \#40. Sampel dikelompokkan menjadi dua, masing- masing terdiri dari 6 gigi. Kelompok I diaplikasi pasta $\mathrm{Ca}(\mathrm{OH})_{2}$ dengan bahan pencampur khlorheksidin diglukonat $2 \%$ dengan perbandingan 1,2 $\mathrm{gml}^{-1}$ menggunakan lentulo \#40. Aplikasi $\mathrm{Ca}(\mathrm{OH})_{2}$ sampai memenuhi saluran akar gigi yaitu keluar melalui korona dan terlihat dari foramen apikal. Kelompok II diaplikasikan pasta $\mathrm{Ca}(\mathrm{OH})_{2}$ dengan bahan pencampur gliserin, digunakan cara yang sama dengan kelompok sebelumnya. Seluruh kavitas ditumpat sementara dan dilakukan foto radiograf. Seluruh sampel disimpan dalam inkubator pada suhu $37^{\circ} \mathrm{C}$ selama tujuh hari.

Masing-masing kelompok dilakukan irigasi salin $0,9 \%$ sebanyak $1,5 \mathrm{ml}$ menggunakan jarum irigasi $1 \mathrm{~mm}$ dari panjang kerja, dilanjutkan menggunakan K-file \#40 dengan gerakan sirkumferensial filing sepanjang kerja sebanyak 15 kali. Irigasi menggunakan salin $0,9 \%$ sebanyak $1,5 \mathrm{ml}$ dan dibiarkan menggenangi saluran akar selama 1,5 menit, dilakukan pengulangan satu kali. Apikal patensi menggunakan K-file \#10. Finalrinse menggunakan salin 0,9\% sebanyak $1,5 \mathrm{ml}$.

Seluruh gigi dipotong dalam arah sagital menggunakan bur diamondfissure tapered kecepatan tinggi. Masing-masing sampel dilakukan pengambilan gambar menggunakan kamera digital di bawah mikroskop stereo dengan pembesaran 120x. Hasil gambar tersebut dimasukkan ke dalam program UTHSCSA versi 3, dilakukan perhitungan luas permukaan sepertiga apikal dinding saluran akar gigi dan luas $\mathrm{Ca}(\mathrm{OH})_{2}$ yang tersisa dalam saluran akar gigi (Balvedi dkk., 2010).

Data hasil penelitian dilakukan uji normalitas menggunakan uji Shapiro-Wilk dilanjutkan uji homogenitas dengan uji Levene Test. Jika data hasil penelitian menunjukkan hasil normal dan homogen, dilanjutkan dengan T-testdengantingkat signifikansi pada $\mathrm{p}<0,05$. 


\section{PEMBAHASAN}

Nilai sisa $\mathrm{Ca}(\mathrm{OH})_{2}$ pada sepertiga apikal dinding saluran akar gigi didapat dari persentase perbandingan luas permukaan sepertiga apikal dinding saluran akar gigi (3 mm bagian apikal) yang tertutup $\mathrm{Ca}(\mathrm{OH})_{2}$ dalam $\mathrm{mm}^{2}$ dibandingkan dengan luas permukaan sepertiga apikal dinding saluran akar gigi ( $3 \mathrm{~mm}$ bagian apikal) dalam $\mathrm{mm}^{2}$ menggunakan program UTHSCSA versi 3.

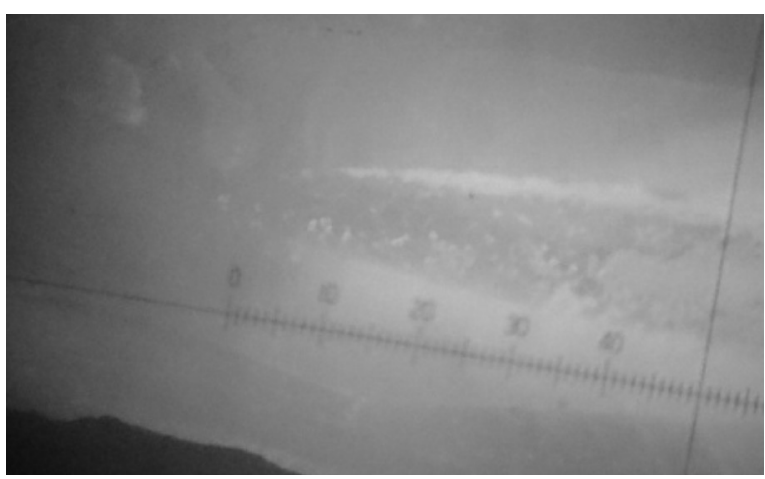

Gambar 1.Sampel dibawah mikroskop stereo dengan pembesaran 120x.Sisa $\mathrm{Ca}(\mathrm{OH})_{2}$ yang menempel pada dinding saluran akar terlihat berwarna lebih opaque dibandingkan dengan warna dentin dinding saluran akar.

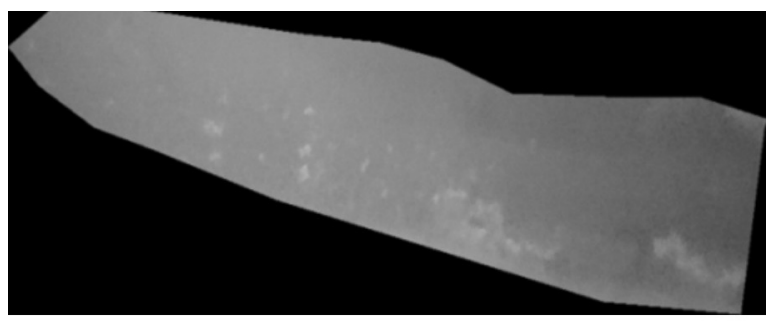

a

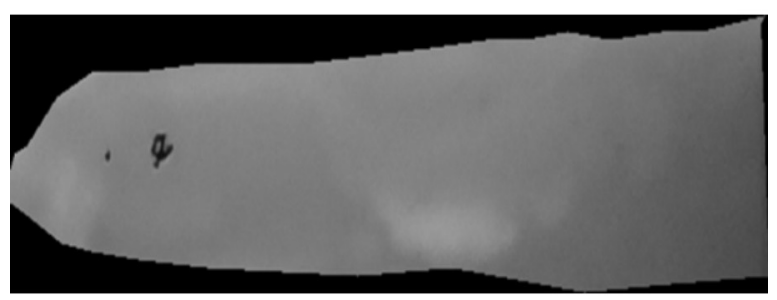

b

Gambar 2. Penghitungan sisa $\mathrm{Ca}(\mathrm{OH})_{2}$ menggunakan program UTHSCSA versi 3.

(a)Kelompok bahan pencampur khlorheksidin diglukonat $2 \%$.(b) Kelompok bahan pencampur gliserin
Tabel 1

Nilai rerata dan standard deviasi sisa $\mathrm{Ca}(\mathrm{OH})_{2}$ dengan bahan pencampur khlorheksidin diglukonat 2\%dan gliserin (dalam satuan \%).

\begin{tabular}{lllc}
\hline No & $\begin{array}{c}\text { Jenis Bahan } \\
\text { Pencampur }\end{array}$ & N & $\begin{array}{c}\text { Sisa Ca(OH) } \\
\mathbf{X} \pm \text { (\%) }\end{array}$ \\
\hline 1 & $\begin{array}{l}\text { Khlorheksidin } \\
\text { diglukonat 2\% }\end{array}$ & 6 & $7,90 \pm 1,986$ \\
2 & \begin{tabular}{l} 
Gliserin \\
\hline
\end{tabular} & 6 & $16,30 \pm 1,479$ \\
\hline
\end{tabular}

Keterangan:

$\mathrm{SD}=$ standar deviasi

$\mathrm{n}$ = jumlah sampel

Hasil pengukuran luas sisa $\mathrm{Ca}(\mathrm{OH})_{2}$ menggunakan program UTHSCSA versi 3 dapat dilihat pada tabel 1. Berdasarkan tabel 1 diketahui bahwa nilai rerata sisa $\mathrm{Ca}(\mathrm{OH})_{2}$ dengan bahan pencampur khlorheksidin diglukonat $2 \%$ sebesar $7,90 \quad \pm 1,986$. Nilai rerata bahan pencampur gliserin sebesar 16,30 $\pm 1,479$. Hasil uji ShapiroWilk menunjukkan bahwa semua data terdistribusi normal $(p>0,05)$. Uji Levene's Test menunjukkan variansi antar-kelompok perlakuan homogen $(p>0,05)$. Hasil T-test terdapat perbedaan bermakna antara kelompok bahan pencampur khlorheksidin diglukonat $2 \%$ dan gliserin terhadap nilai sisa $\mathrm{Ca}(\mathrm{OH})_{2}$ dengan nilai $\mathrm{p}<0,05$.

Pada tabel rerata menunjukkan sisa $\mathrm{Ca}(\mathrm{OH})_{2}$ pada kelompok bahan pencampur gliserin mempunyai nilai yang lebih besar dibandingkan dengan kelompok bahan pencampur khlorheksidin diglukonat $2 \%$. Hal ini sesuai dengan penelitian sebelumnya yang menjelaskan bahwa bahan pencampur $\mathrm{Ca}(\mathrm{OH})_{2}$ dengan viskositas yang lebih tinggi (gliserin) lebih sulit dibersihkan jika dibandingkan dengan bahan pencampur encer (khlorheksidin diglukonat 2\%). Penambahan gliserin menyebabkan pasta $\mathrm{Ca}(\mathrm{OH})_{2}$ bersifat lengket dan melekat erat terhadap dinding saluran akar gigi (Nandini dkk., 2006).

Pada uji T-test menunjukkan adanya pengaruh penggunaan bahan pencampur $\mathrm{Ca}(\mathrm{OH})_{2}$ yaitu khlorheksidin diglukonat $2 \%$ dan gliserin terhadap sisa $\mathrm{Ca}(\mathrm{OH})_{2}$. 
Hal ini sesuai dengan teori Viskositas Newton menyatakan bahwa kekuatan geser dipengaruhi oleh viskositas cairan, semakin tinggi viskositas maka dibutuhkan gaya yang besar untuk menggeser suatu benda (So dkk., 2005). Gliserin mempunyai viskositas lebih tinggi sehingga membutuhkan gaya yang lebih besar untuk melepaskan pasta tersebut dari dinding saluran akar gigi. Gaya yang dihasilkan bahan irigasi yang menggunakan jarum safe-ended yaitu arus turbulen. Arus turbulen yang dihasilkan kemungkinan tidak cukup mampu melarutkan pasta $\mathrm{Ca}(\mathrm{OH})_{2}$ dengan bahan pencampur gliserin dari dalam saluran akar gigi.

Terdapat perbedaan nilai rata-rata berat jenis kedua bahan pencampur. Khlorheksidin diglukonat $2 \%$ mempunyai berat jenis 1,07 $\mathrm{gcm}^{-3}$ sedangkan gliserin mempunyai berat jenis lebih besar yaitu 1,25 $\mathrm{gcm}^{-3}$. Dengan berat jenis yang lebih besar, kemungkinan menyebabkan pasta $\mathrm{Ca}(\mathrm{OH})_{2}$ dengan bahan pencampur gliserin lebih mudah mengendap sebelum pasta tersebut mengalir mencapai koronal. Hal tersebut menyebabkan sisa pasta $\mathrm{Ca}(\mathrm{OH})_{2}$ dengan bahan pencampur gliserin dalam dinding saluran akar gigi lebih banyak dibandingkan dengan bahan pencampur khlorheksidin diglukonat $2 \%$.

Secara kimiawi, pasta $\mathrm{Ca}(\mathrm{OH})_{2}$ dengan bahan pencampur gliserin tidak dapat terurai. Dengan tingkat keasaman yang lemah, maka $\mathrm{Ca}(\mathrm{OH})_{2}$ tidak mampu melepas ion $\mathrm{H}^{+}$dari gliserin. Hal ini dibuktikan dengan derajat kelarutan asam (pKa) yang lebih besar dari khlorheksidin diglukonat 2\% (pKa gliserin= 14,2 dan pKa khlorheksidin diglukonat $2 \%=10,78$ ). Kelompok bahan pencampur khlorheksidin diglukonat2\% menunjukkan terdapat sisa $\mathrm{Ca}(\mathrm{OH})_{2}$ lebih sedikit dibandingkan dengan gliserin. Hal ini kemungkinan karena khlorheksidin diglukonat 2\% mampu bereaksi dengan $\mathrm{Ca}(\mathrm{OH})_{2}$. Hasil reaksi tersebut akan membentuk garam kalsium diglukonat (Boutsioukis dkk., 2013). Dengan penambahan bahan irigasi maka garam tersebut akan mudah larut. Hal ini mungkin menyebabkan pasta $\mathrm{Ca}(\mathrm{OH})_{2}$ dengan pencampur khlorheksidin diglukonat 2\% lebih mudah dibersihkan dari dalam saluran akar gigi.

Pada penelitian ini sisa $\mathrm{Ca}(\mathrm{OH})_{2}$ berkisar antara 7,90-16,30\%, angka ini lebih kecil jika dibandingkan dengan penelitian sebelumnya yang berkisar antara $45-50 \%$ pada sepertiga apikal saluran akar gigi (Balvedi dkk., 2013). Hal ini kemungkinan disebabkan karena waktu agitasi lebih lama dibandingkan dengan penelitian sebelumnya. Waktu aktivasi ultrasonik mempengaruhi tingkat kebersihan saluran akar. Semakin lama aktivasi ultrasonik di dalam saluran akar, maka dapat meningkatkankebersihan dinding dentin saluran akar. Pemilihan smooth wire dengan diameter lebih kecil mungkin dapat membersihkanCa $(\mathrm{OH})_{2}$ lebih efektif. Pada penelitian ini digunakan smooth wire berukuran \#15, ukuran file mempengaruhi kecepatan pergerakan bahan irigasi, aliran menjadi lebih lambat jika digunakan file dengan ukuran yang besar (van der Sluis dkk., 2007).

Pada penelitian ini, pembelahan gigi secara sagital sulit dilakukan secara tepat sehingga kemungkinan terdapat sisa $\mathrm{Ca}(\mathrm{OH})_{2}$ tetutup oleh dinding dentin yang menyebabkan sisa $\mathrm{Ca}(\mathrm{OH})_{2}$ tidak terhitung. Kemungkinan juga terdapat material $\mathrm{Ca}(\mathrm{OH})_{2}$ yang hilang selama pengeburan. Analisis menggunakan foto digital tidak mampu menghitung sisa $\mathrm{Ca}(\mathrm{OH})_{2}$ secara tepat karena foto digital memberikan gambaran dua dimensi, sehingga $\mathrm{Ca}(\mathrm{OH})_{2}$ yang dihitung hanya pada lapisan superfisial.

\section{SIMPULAN}

Berdasarkan hasil penelitian yang telah dilakukan, dapat disimpulkan bahwa bahan pencampur khlorheksidin diglukonat $2 \%$ menyisakan sisa $\mathrm{Ca}(\mathrm{OH})_{2}$ lebih sedikit dibandingkan penggunaan bahan pencampur gliserin pada sepertiga apikal dinding saluran akar gigi. 
Disarankan bagi klinisi untuk memilih bahan pencampur $\mathrm{Ca}(\mathrm{OH})_{2}$ menggunakan khlorheksidin diglukonat $2 \%$ agar lebih mudah menghilangkan $\mathrm{Ca}(\mathrm{OH})_{2}$ pada sepertiga apikal dinding saluran akar. Disarankan bagi klinisi untuk memilih bahan pencampur $\mathrm{Ca}(\mathrm{OH})_{2}$ menggunakan khlorheksidin diglukonat $2 \%$ agar lebih mudah menghilangkan $\mathrm{Ca}(\mathrm{OH})_{2}$ pada sepertiga apikal dinding saluran akar. Sebaiknya penelitian selanjutnya dapat dilakukan menggunakan perangkat yang mampu menghasilkan gambaran tiga dimensi sehingga dapat menghitung volume sisa $\mathrm{Ca}(\mathrm{OH})_{2}$ lebih tepat.

\section{DAFTAR PUSTAKA}

Balvedi,R.P.A., Versiani,M.A, Manna,F.F., Biffi,J.C.G., 2010, A Comparison of Two Techniques for the Removal of Calcium Hidroxide from Root Canals, Int Endod J, 43:763-8.

Boutsioukis,C.,

Kastrinakis,E., Lambrianidis,T., $\quad$ Verhaagen,B., Versluis,M., dan van der Sluis,L.W.M., 2013, formation and removal of Apical Vapor Lock During Syringe Irrigation: a Combined Experimental and Computating Fluid Dynamics Approach, Int Endod J,47:1-11.

Boutsioukis,C., Verhaagen,B., Versluis,M., Kastrinakis,E., Wesselink,P.R., Van Der Sluis,L.W.M., 2010, Evaluation of Irrigant Flow in the Root Canal Using Different Needle Types by an Unsteady Computational Fluid Dynamics Model, J Endod,36(5):875-80.

Fava,L., dan Saunder,W., 1999, Calcium Hydroxide Paste: Classification and Clinical Indications, Int Endod J., 32:257-82.

Hosoya,N., Kurayama,H.,Lino,F., Arai,T., 2004, Effect of Calcium Hydroxide on Physical and sealing Propertis of Canal Sealers, Int Endod J, 37:178-84.

Khosy,M., Prabu,M., dan Prabhakar,V., 2011, Long Term of Calcium Hydroxide on the Microhardness of Human Radicular Dentin A Pilot Study, The Internet Journal of Dental Science,9(2).

Kusuma,A.R.P., Mulyawati,E., Nugraheni,T., 2013,PengaruhLamaKontakCampuran Kalsium Hidroksida-Gliserin dan Kalsium Hidroksida-Chlorhexidine Digluconate 2\% Terhadap Kekerasan Mikrodentin pada Segmen Sepertiga Sarvikal Saluran Akar, Jurnal Kedokteran Gigi, 4:39-44.

Nandini,S., Velmurugan,N., Kandaswamy,D., 2006, Removal Efficiency of Calcium Hydroxide Intracanal Medicament with Two Calcium Chelators: Volumetric Analysis Using Spiral CT, An In Vitro Study, J Endod, 32:1097-101.

Rao,S.A., dan Manasa,N., 2012, Effect of Irrigants Using Ultrasonics on Intracanal Calcium Hydroxide Removal-An In Vitro Comparative Evaluation, Braz J Oral Sci, 11:52-5.

So,H.Y., Kim,Y.K., Park,J.W., dan Kim,S.K., 2005, Chemical Reaction Between calcium Hydroxide and Chlorhexidine Diglukonat, The Preliminary Program for $24^{\text {th }}$ Annual Academic Session and the $22^{\text {nd }}$ General Meeting.

Spangberg,L., dan Haapasalo,M., 2002, Rationale and Efficacy of Raat Canal Medicament $s$ ang Root Canal Materials with Emphasis on Treatment Outcome, Endod Topic, 2:35-58.

Van der Sluis,L.W.M., Versluis,M., Wu,M.K., Wesselink,P.R., 2007, Passive Ultrasonic Irrigation of the Root Canal: A Review of the Literature, Int Endod J, 40:415-26. 